\title{
HISTORY OF SNOW-COVER RESEARCH
}

\author{
By S.C. COLBECK \\ (U.S. Army Cold Regions Research and Engineering Laboratory, Hanover,
}

New Hampshire 03755-1290, U.S.A.)

\begin{abstract}
The history of snow-cover research is divided into four distinct periods. Before 1900 there were systematic observations of snow but the tools were just being developed to begin serious research. From 1900 to 1936, many investigations were made because of the practical considerations of snow hydrology and snow avalanches. Individuals began the assessment of snow water equivalent for forecasting run-off and the observation of snow structure and texture. Quantitative and physical investigations quickened after government-sponsored laboratories were established in 1936, the same year as the founding of the International Glaciological Society. From 1936 through the 1960s, many detailed investigations were made into snow's physical properties and behavior. Professional societies organized national and regional meetings, and published the results of snow research. Many more laboratories became involved as knowledge about snow was developed and applied to run-off forecasting and avalanche defense. Snow research surged again during the 1970 s with the establishment of a new generation of snow scientists using more advanced theory, computers, and instrumentation. As demands continue for solutions to snow problems with new emphasis on old themes, snow research generates knowledge about snow for a wide variety of applications.
\end{abstract}

\section{INTRODUCTION}

Most of the land mass in the Northern Hemisphere is snow-covered at some time (Fig. 1). While people in northern or mountainous climates try to adapt to long-term snow covers, most of the temperate zones struggle through intermittent snow events that disrupt normal life. As our society has advanced, we have developed some of the technology to deal with snow and have made greater use of snow as a natural resource. Nevertheless, much of our technology is very vulnerable to snow. For example, modern armies are limited by snow in ways never dreamed of by Hannibal.

Much of the history of snow-cover research revolves around two major themes - water resources and avalanches. These "good and evil" aspects of the snow cover are the main parts of mankind's highly ambivalent relationship with snow. Much of the early attention focused on the snow cover was due to these two subjects, and they still explain and justify most of the snow research we do today. Furthermore, an entire industry is based on snow. The profitability of ski areas and their accessory suppliers is so dependent on the quality and quantity of snow that the manufacture of the snow itself is now necessary in many places. Of course, the benefits to be realized by making more snow on a ski slope or efficiently clearing natural snow from a highway are partly counteracted by avalanches of Man-made snow and frost heaving on roads.

Throughout the history of snow research we have steadily increased our understanding of snow's behaviour in a wide variety of situations. Unfortunately, this progress has not yet allowed us to forecast avalanches with enough certainty to reduce the hazards or to measure remotely the snow inventory for hydrological forecasts. In fact, in some cases the net result of our research is to provide an understanding of why we cannot solve a problem. Nevertheless, as human activity extends farther into snowy regions and an ever-increasing variety of snow-connected problems is added to the older ones, application of the knowledge we have gained is more essential to our continued activities over snow-covered terrain.

The history of snow research is described in four successive periods (Table I) whose size decreases as we progress through them. Until 1900, many basic tools and concepts were being developed for use in a variety of fields. From 1900 to just prior to World War II, a wide

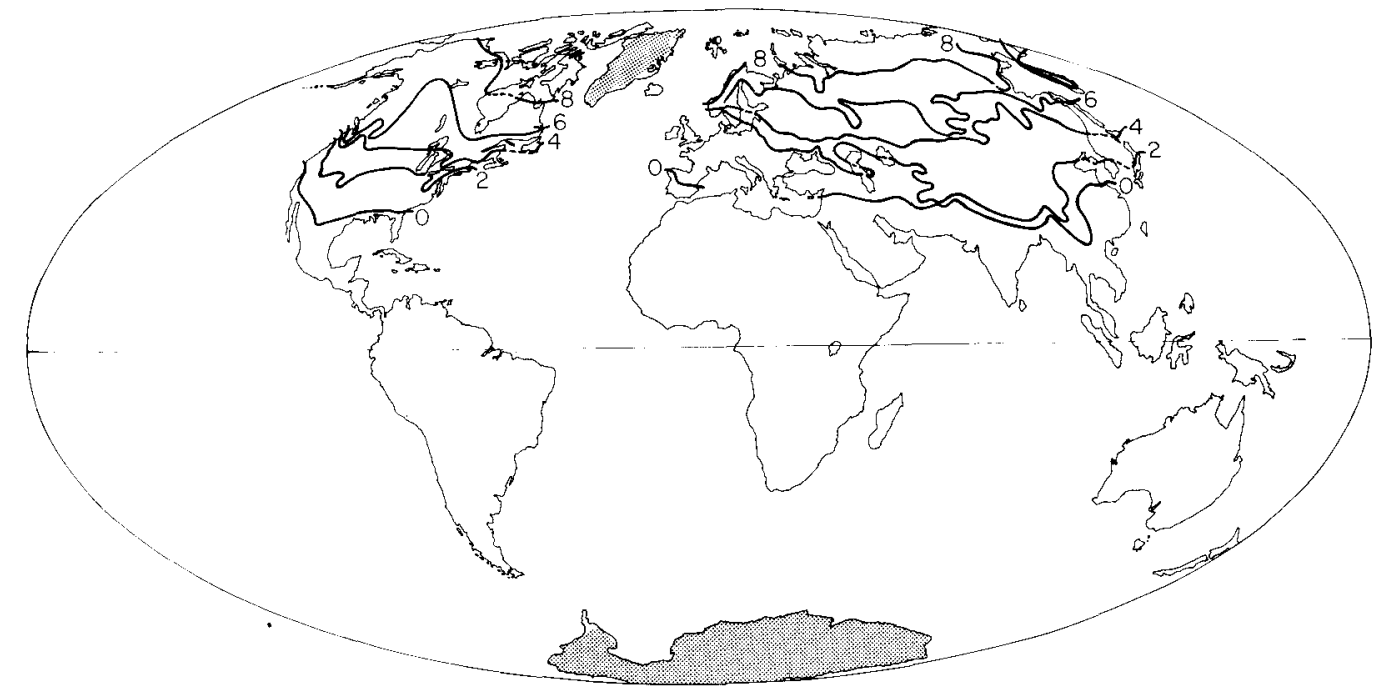

Fig. 1. Limit of the snow cover. The numbered lines represent the duration of the snow cover in months. 


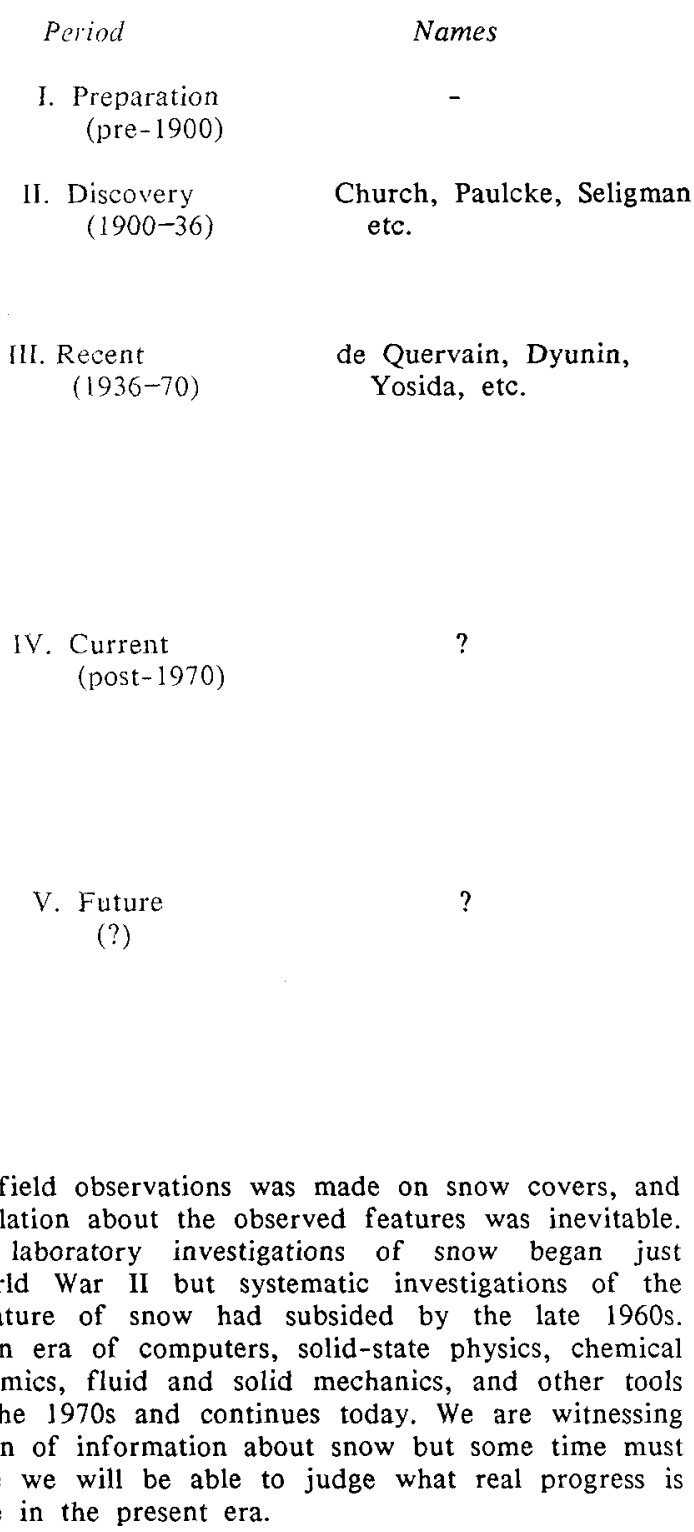

variety of field observations was made on snow covers, and some speculation about the observed features was inevitable. Controlled laboratory investigations of snow began just before World War II but systematic investigations of the physical nature of snow had subsided by the late 1960s. The modern era of computers, solid-state physics, chemical thermodynamics, fluid and solid mechanics, and other tools began in the 1970 s and continues today. We are witnessing an explosion of information about snow but some time must pass before we will be able to judge what real progress is being made in the present era.

\section{PREPARATION (PRE-1900)}

Before 1900, many people probably made casual observations on the snow cover but left no written record for us to examine. For example, the Icelandic farmer/ scientists were curious about a wide range of glaciological phenomena. The first reported work on snow was merely the observation of snow dendrites, but that was well before the development of the microscope, which would have allowed smaller crystals to be observed as well. Crystals in the snow cover were not observed in a systematic way until 150 years after the microscope was developed. In the $1800 \mathrm{~s}$ there were many reports of observations of crystals in the snow cover as well as early work on snow properties, especially thermal conductivity. The European countries were the center of this early work and established the first systematic observations of snow conditions such as depth, areal extent, texture, density, and temperature. At about the same time, Europeans were quantifying ideas about capillarity, vapor pressure and temperature, and vapor pressure and curvature, thus setting the conditions for rapid advances in understanding the basic nature of the wide range of snow textures. Even observations of life in snow were made in this period, and work on snow and avalanches was done in the Alpine countries, but the most significant events were really the development of tools that would be applied later to the study of snow.
Accomplishments

Some early observations on snow but tools and concepts were just being developed

Routine measurements established. Concepts from physics provided qualitative insights. Progress on avalanches and snow-melt runoff

Government-sponsored laboratories established and professional societies founded. Snow research becomes more quantitative. International community established. Surface energy exchange quantified. Many physical processes investigated including models of processes and properties. Widespread use of models for engineering purposes

Tools become much more sophisticated. Concepts from other fields refined and applied to snow to make significant advances. Some of the "classic problems" solved but others remain. Older models and terms replaced but many problems still not completely solved

Grain-scale geometry of snow quantified and this information used to develop models of physical processes and properties for a wide range of snow types. These models widely used to describe snow in engineering

\section{DISCOVERY (1900-36)}

With basic scientific principles and instruments available, knowledge about snow could now be developed. The few observations, property determinations, and routine measurement programs in place before 1900 were quickly supplemented by activity throughout Europe, North America, and Japan. Most of the activity was motivated by a basic interest in hydrology or avalanches, although there was interest in transportation and basic science as well. However, in this period the age-old problems of the snow cover were attacked by new techniques, and a basis was provided for the more quantitative work that would follow. The early settlers who struggled through snowy winters or Hannibal's experience in the Alps were associated with the past. With increased use of motorized transportation, competition for scarce water resources of the booming western United States, and increased recreational use of the Alps, the needs for knowledge about the snow cover grew.

In spite of the increased benefits and problems of the seasonal snow cover, it was individuals rather than governments that did the research or started the programs. Seligman's (1936) observations on the snow cover in the Alps and Church's (1914) measurement of the snow inventory in the Sierra Nevada are examples of the pattern of observations, analysis, and publication that was established. Of course, many other people contributed as well, but I will discuss how the discipline evolved rather than the work that was done.

The interest in snow hydrology was far more comprehensive than just the snow surveys, but the surveys still provided the most essential data for run-off forecasts on a seasonal basis. There was a great deal of interest in the energy exchange at the surface of a melting snow cover involving a variety of countries but again limited to Europe and North America. The published work included smallscale observations on the albedo by Angstrom (1925) and general descriptions by Horton (1915) and Karpov (1936). Attempts were made to understand radiation penetration and absorption as well as the mechanisms of heat transfer and evaporation (e.g. Loewe, 1927). The acceleration of snow 
melting by scattering dark substances, snow retention in agricultural fields for protection of winter crops, the influence of forests on snow distribution, and many other subjects were treated. The most technical work, such as the observations of energy exchanges, was constrained by the nature of the instrumentation available at that time but was still far more sophisticated than the work done in the earlier period.

Although Darcy had developed the law of saturated flow through porous media in the mid-1800s and that law was extended to unsaturated flow in the 1930 s, these ideas were not applied to snow until much later. The thermal conductivity of snow continued to be investigated in a quantitative way in Japan, the U.S.S.R., and the Alpine countries. In this period the systematic investigations of blowing snow began in the U.S.S.R. and received much attention, probably because of the effect of wind transport on winter wheat. The first observations of microwave propagation over snow were made in Japan, and the electrical resistivity of snow was measured.

The importance of snow to transportation was expressed repeatedly in this period, including concern about logging sleds in Canada, hardness and strength measurements in Japan, over-snow mobility, snow fences, snow plowing and chemical melting in the U.S.S.R., and the construction of motorized sleds in various countries. Snow control on roads developed throughout the temperate and sub-Arctic regions as dependence on motorized transportation grew.

Much interest was shown in the compaction of snow into ice on glaciers (e.g. Ahlmann and Tveten, 1923), including Sorge's well-known observations in Greenland. Studies of the metamorphism of snow grew during this period because of the accelerated interest in snow properties. The interest in snow avalanches, especially in Switzerland but in many other countries too (e.g. Ferrara, 1916), led to detailed observations of the formation and evolution of snow covers. The observations and descriptions were largely qualitative but provided the basis for a surge of quantitative work later. The work of Paulcke (e.g. 1938) who classified and illustrated metamorphism, and the classic book of Seligman (1936) are the outstanding examples. Because of his extensive observations, I still use Seligman's book 50 years after its publication, although I often disagree with his interpretations of the processes behind the observed phenomena.

The early work on snow and avalanches in Switzerland and the establishment of the Swiss Commission on Snow and Avalanche Research to oversee that work has been described by Haefeli (1937). The importance of developing avalanche forecasting and protection continued to grow, and the response to avalanches and other snow problems was the establishment of not only commissions but laboratories dedicated to snow and ice research. Thus, as snow surveying for hydrological purposes was spreading around the world, laboratories dedicated exclusively to snow and ice research were started.

\section{RECENT (1936-70)}

The formalization of snow research by the establishment of government laboratories changed forever the character of snow studies. The founding of the laboratories such as those at Davos and Sapporo were perhaps the most significant events in the history of snow studies. More or less coincident with this was the founding of professinal organizations, which facilitated communication among a growing international community of snow scientists. The International Glaciological Society was established in 1936 by a prominent snow scientist, and the Society has been active in publishing and conference organization since then. The Japanese Society of Snow and Ice was established 3 years later. The International Commission on Snow and Ice has been active in its present form since 1939. The American Geophysical Union was very active in snow research in the 1930 s but is now mostly limited to publishing. The National Association for the Study of .Snow and Avalanches is very active in France, and three smaller organizations hold conferences in North America. Snow science advanced rapidly in this period partly because of these organizations.

Government and university institutes dedicated at least partly to snow research were established in most countries with significant snow covers. In fact, the field developed enough in this period that nearly 20 bibliographies were prepared on the results of snow research. Further evidence of the growing community of snow scientists is shown by the large number of papers written about the progress of snow research in particular countries. Bekker (1951) on Germany, de Quervain (1950) on North America compared to Switzerland, Johnson and Bader (1947) on Switzerland, Tonini (1958) on Italy, Legget (1949) on Canada, Japanese Society of Snow and Ice (1949) on Japan, Angervo (1952) on Finland, and Richter (1961) on the U.S.S.R. are examples.

Snow research in many ways benefited from World War II in spite of the obvious break-down in international communications and shifts in national priorities. Most of the government laboratories were established just before, during or after the war, and some were run by the military. During the war, research on airfields and roads increased but other snow research was conducted and published in Japan, North America, and Europe as if the conflict never existed. Following the war, snow research was again dominated by interests in hydrology and avalanches, although the variety of interest behind snow research is always increasing. Much effort was put into the development of general hydrological models, and these included sub-routines for forecasting snow-melt run-off, especially in the western United States where competition for water resources was growing. Some years of work at the western snow laboratories, especially the Central Sierra Snow Laboratory established in 1943, was summarized in U.S. Army Corps of Engineers (1956), which represented a significant step forward in the decade following World War II. With the introduction of digital computers for hydrological forecasting, information about the snow cover was needed. Even the models in current use contain very little information about the physical properties of snow but, as these models are placed on a more physical basis, more detailed knowledge of the physical processes in snow must be available. Even if the models are just based on the hydrological record in a particular area, they require much input data. For seasonal forecasting, the snow inventory over a watershed is needed, and much effort is spent acquiring these data by laborious methods in many parts of the world. The introduction of automated methods like the pressure pillow and the gamma-ray gauge helped establish continuous readings at remote sites, but these methods are still point samplers and have their own sets of problems too. Large-scale measuring techniques are needèd to overcome the limitations of point measurements but, other than for photography of snow-covered areas and gamma-ray flights along pre-set lines, remote sensing has not yet shown great promise. The use of microwaves in either the active or the passive mode is very attractive because of their allweather capability, but it requires the interpretation of complex signals. This interpretation requires extensive knowledge of the interaction of microwaves and layered snow covers, which requires a very good understanding of the physical nature of snow and the physics of scattering and absorption at microwave frequencies. The problems are very complex but, through investigations of the physical processes in snow and dielectric properties of snow started in this period, progress has been made.

During this period there was a great deal of emphasis on the surface-energy exchange over snow. The availability of both new instruments and theory led to a very high level of understanding of the various components of heat and mass exchange. Furthermore, this knowledge was developed at a sufficiently basic level that it could be used under a variety of conditions. In some senses, this was the greatest achievement of basic research on snow through the 1960 s because the basic processes were well described. Unfortunately, not much use could be made of this information, partly because other parts of the snow-melt cycle were not treated in a similar way.

Sverdrup (1936) made the first application to the snow cover of heat-transfer theory, followed by the extensive investigations at the snow laboratories in the western United States (U.S. Army Corps of Engineers, 1956) and concurrent work in the Soviet Union (e.g. Kuz'min, 1961). Heat and 
mass transfer was analyzed in terms of individual components, each one of which could be calculated or measured using procedures that were still being refined by micro-meteorologists. Interest in snow-melt aroused considerable interest in surface albedo and in the general optical properties of snow. As was done with other subjects during this period, models of scattering and absorption were developed to promote a better understanding of the physical processes, experiments were conducted to provide a data base against which the models could be tested, and field observations provided information about the natural situation. Because of snow's very complicated and wide range of crystal geometries, it is not surprising that those efforts were only partly successful and that some things were left to be explained later.

Another example of modeling is the effort directed toward understanding heat flow within snow, a subject that is complicated not just by the geometry, but by grain-tograin vapor flow as well. Much of this work was done by and has been described by Yosida and others (1955) and Yen (1969). Simple solutions to this problem are ruled out by the complicated heat-flow paths through snows of a wide range of geometries and grain types. Problems of structural parameters can only be attacked through stereology, a subject we are just bringing to snow research. Heat flow can be accurately measured, and it is not surprising that there is a lot of variation in measured thermal conductivity at any given density because of the varying grain types and inter-grain connections. Our ideas about this subject have not progressed markedly since this period and, except for the introduction of natural convection into the problem, they probably will not progress greatly until we find a way to deal with the structure of snow.

The understanding of avalanches, the other major problem area of snow studies, was also placed on a solid foundation during this period. As in hydrology, essentially new areas of investigation were established and developed to a high level of understanding. This included avalanchespecific topics like run-out models and more general topics like snow mechanics.

While the first work on avalanche dynamics may have been in the U.S.S.R., Voellmy's (1955) model of a flowing avalanche was really the starting point for the quantitative treatment of this important subject. This work was soon refined and applied to establish guidelines for avalanche run-out characteristics for many problems of immediate concern in populated areas of mountainous countries. Models of this type require somewhat arbitrary choices of parameters, so efforts continue to develop models that are more physically based. Nevertheless, the start towards a final solution provided by Voellmy is typical of many efforts made in this period.

With the development and widespread use of theories of continuum mechanics, elasticity, and plasticity, the conceptual and quantitative treatment of snow mechanics, snowslope creep and glide, and snow-slope failure was possible. This work was largely initiated in the Alpine countries because of avalanche problems, but interest in basic snow mechanics spread to other fields and other countries in the 1950 s. In one of the publications that marks the beginning of this period (Bader and others, 1939), Haefeli started the study of snow mechanics with the application of ideas from soil mechanics, but it was inevitable that snow would have to find its own theoretical basis because of its highly compressible nature. Any investigation into a physical property of snow is complicated by the ever-changing grain-size and shapes as well as the constantly increasing density of snow. Accordingly, work in this period was mostly designed to provide the data necessary for a large range of observations over a variety of conditions and to establish theories based on simple concepts like springs and dashpots. Mellor's (1975) review is mostly of that period.

Such work as Bader's observations of the destruction of snowflakes (Bader and others, 1939), Yosida's recognition of the grain-by-grain movement of water vapor from warm to cold (Yosida and others, 1955), and de Quervain's laboratory experiments (e.g. de Quervain, 1963) provided a basis for thinking about snow metamorphism that is still useful today. While the basic thermodynamics had all been developed, the necessary knowledge about crystal growth was just being generated and, in fact, ice-crystal growth was only being observed at very high supersaturations. The physical models of vapor flow only represented the processes in snow in a qualitative way because " they were limited to one-dimensional flow between parallel plates or to continuity arguments. The one-dimensional flow illustrated the principles but could not be forced to represent snow, and nothing was learned about grain growth from the continuity approach. Nevertheless, much of the conceptual foundation was laid out and the experiments provided insights into what had been observed in snow covers. The growth of intergranular bonds through sintering was intensively studied and developed to a comparatively high state of understanding partly because only local geometry needed to be considered to explain the shapes that were observed. The use of thin sections was introduced in Austria and Switzerland in this period. This was a necessary step before the introduction of stereology, which may provide the needed information about snow structure in the future.

While avalanches led to interest in snow mechanics and metamorphism, results from studies of blowing snow were rarely applied to avalanche problems until after this area of study was fairly well developed. Two approaches dominated the progress in this field, one developed with work in Antarctica (e.g. Budd, 1966) and the other in the U.S.S.R. (e.g. Dyunin, 1967). In addition to describing these distinctive modes of transport, as was typical of this period, much data were collected to provide a general understanding of the phenomenon, and laboratory techniques were developed to simulate snow drifting around objects. Thus data, theory, and partial solutions to applied problems all evolved.

In some cases, these earlier investigations have not survived the "test of time" but in other cases the work is still used today. For example, Cumming's (1952) investigation of the dielectric properties of snow at microwave frequencies is an example of a basic study not motivated by either avalanches or hydrology. Nevertheless, this and subsequent work in this area is of interest to both fields today. The basic research done by others during this period in a variety of areas formed most of the basis for later work such as Anderson's (1976) model of snow accumulation and melt. Without the basic information about a wide variety of areas within snow research developed during the period, the next generation of snow scientists would not have been in a position to take advantage of the wide range of new tools and approaches that became available.

\section{CURRENT (POST-1970)}

In strict terms, there are no distinct generations of scientists, and yet these four periods of snow research are distinguishable by contributions by certain researchers. As Paulcke, Seligman, and Church were to pre-1936, Yosida, de Quervain, and Dyunin were to 1936-70. The point is not that these and other researchers disappeared after their period but rather that their major research contributions were in a distinct period and their later contributions were more towards administration, teaching, consulting, and/or professional activities (like writing reviews).

Since the current period is still evolving and since I am involved in it, it is risky for me to judge its successes and to choose the names that will be remembered two generations from now, as Church and Seligman are today. It is clear that the last period provided us with a good foundation on which to build and that the tools are much better today than they were 40 years ago. However, it is also true that many problems for which the tools were already available were not solved. As mentioned earlier, the first experiments on unsaturated flow in porous media were done in the 1930 s but these concepts were not applied to snow until the 1970s. Finite-element solutions to determine the state of stress in a slab of snow came long after this technique was used in other fields. These lags are not surprising, since snow researchers have almost always applied procedures, equipment, and concepts developed in other fields but the converse has rarely been true. Nevertheless, at the start of the current period there were a number of outstanding problems that could have been solved earlier. There were also some "classic problems" left to the next 
generation, some of which have yet to be solved. These problems include avalanche run-out distance and impact forces, the existence and effects of natural convection in snow, remote-sensing techniques for snow inventory, the flip-flop between rounded and faceted crystal growth, and many more.

Although digital computers were widely used before 1970, they have been used considerably more by snow scientists since that time. This partly explains the current success in attacking problems that require mathematical models. In addition to using more advanced equipment as it has become available, some of the poorly conceived tools of the past have been rejected and far more satisfactory replacements found. One of the most basic parameters one can measure in snow, the liquid water content, was originally determined by centrifuging or melting calorimeters, both of which have severe limitations. There are now a variety of methods available, each of which has strengths and weaknesses but all of which give reasonable answers. Radar is no longer just a device used by others who view snow as an obstacle but it is now used to obtain information about snow and flowing avalanches.

The weakness in the use of Voellmy's (1955) model of avalanche run-out was the need to assign some rather arbitrary values to important parameters. While we now have more sophisticated models of avalanches run on computers, we are still limited by a number of obstacles, one of which is still the need to choose rather arbitrary values for some parameters. We do not have a numerical model of a fully turbulent avalanche, and even if we did, we do not yet know enough about the structure of flowing avalanches to know how to use such a model. However, it is clear that the ongoing tests on laboratory simulations of avalanches, radar observations of the structure and speed of avalanches, and improved mathematical models of avalanches are moving us in the direction of increased knowledge. Nevertheless, Voellmy's approach is still used when decisions must be made about the ever-increasing encroachment of buildings in mountainous areas.

The nature of the limitations that we face has changed in each area in which we have made progress. For example, we can calculate surface melting and route melt water through the snow. Thus, we have the physical basis for greatly improved hydrological models, but these models could not be applied to routine forecasting because of the very large amount of data that would be necessary to drive them. Because only a few research sites gather the necessary information, models are often limited to being research tools, although these are often the most powerful tools available for generating knowledge. Just the creation of physical insights or guidelines often justifies the expense of generating a physically based model.

The introduction of new tools is often not an immediate advantage, since new tools of ten require more knowledge of the system being studied. For example, very high-frequency radars are now available to snow researchers but at frequencies where the wavelength is similar to the grain-size. Rather than simply providing a wider range of frequencies with which snow can be studied, these higherfrequency radars present us with the problem that the nature of scattering and absorption is not well understood at those wavelengths. Accordingly, before we can interpret these signals, we have to examine the processes by which the echoes are generated. Thus, the current effect of having this new tool available is that we can use the new tool to investigate the manner in which it interacts with snow. Once we learn to interpret the signals returned from snow, these radars should be useful for both snow research and surveying.

In addition to the continuing investigations of the physical properties of snow, snow chemistry has become a very important topic in the international community because of the world-wide distribution of atmospheric pollutants. Part of the problem is that soluble impurities tend to be washed out of the snow cover with the first fraction of melt water so that, in areas subjected to acid precipitation, there is a significant $\mathrm{pH}$ drop in streams during the onset of snow-melt run-off. The sudden surge of solubles has been observed across the Northern Hemisphere and is sufficiently intense in some regions that it can have drastic effects on aquatic populations. Investigations of this phenomenon use the information developed over the years about snow accumulation, melt, and run-off, as well as techniques developed for handling cores from the ice sheets.

The investigations of this and many other topics have been successful partly because of the combined efforts of theoretical, laboratory, and field projects. All three are really necessary to understand fully the complicated processes behind any problem of significant interest, and researchers in this period have much greater opportunities to utilize fully sophisticated tools and concepts than ever before. This is partly because of the availability of devices like the personal computer but also because of the better education of the current researchers in basic subjects like physics and mathematics. However, no matter what our educational background might be, we could not use stereology without both the computers and the body of theory developed elsewhere. Given the trend in this period towards constructing grain-scale models of the physical processes, the potential use of stereology is very great. It has become clear through the history of snow studies that useful but limited simulations of snow properties can be achieved while treating snow as a continuum. To really develop generally applicable models based on the processes, it is necessary to describe the interactions among the grains for each property of interest. These descriptions should begin with knowledge of the geometry of the compacts for any particular type of snow of interest, and stereology is the best way to get this information. Stereology is, however, limited in what it can describe, and it is not clear at this point that the use of stereology will mark the beginning of the next period of snow research.

Attention to grain-scale interactions and widespread use of stereology are an important characteristic of this period. These are necessarily linked since the purpose of stereology is to provide the information needed to characterize the geometry that controls the interactions among the grains, and without that characterization, grain-scale descriptions would not be very meaningful. Perhaps the start of the next period will be marked by a surge of information about the structure of snow. Right now stereology is bordering on that kind of usefulness but it has not been that productive. The widespread use of personal computers may also characterize the next period because of their usefulness in collecting and managing data as well as their use in modeling experiments. Whatever significant tool(s) or event(s) mark the beginning of the next period, the current period has run for nearly a generation by now and, given the rapid advances in technology, it seems reasonable to expect new developments in the near future.

\section{SUMMARY}

The history of snow-cover research has been described in four periods with distinctly different accomplishments. Before 1900, the tools and concepts for doing serious research were being developed. Before 1936, many individuals made observations of snow, published articles and books describing snow, and started data-collection programs for purposes such as snow hydrology. After 1936 , institutions dominated snow research. Physical modeling and laboratory experimentation were widely used to develop knowledge of the physical processes as well as the macroscopic behaviour of snow. After 1970, many new researchers became active using more advanced concepts, larger computers, and more sophisticated instruments. In this current period, much emphasis has been placed on grain-scale phenomena, since the continuum approach used earlier was necessarily limited by its inability to describe the results of processes in a wide variety of snow types. The success of the current efforts will be determined in part by our ability to characterize snow as an assembly of particles. The successful development of that ability will probably mark the start of a new period of snow research.

As with many other disciplines, snow-cover research began with systematic observations and is now trying to establish physically based models of the processes. Both approaches are necessary but not necessarily sufficient for the solution of a practical problem because of the amount of data which is often necessary to use a model. Neverthe- 
less, we steadily increase our knowledge of the snow cover and provide more information to the people dealing with a large variety of snow problems.

\section{ACKNOWLEDGEMENTS}

I thank Professor M. de Quervain for his comments on the manuscript. My work on the snow cover is supported at CRREL by project 4A161102AT24.

\section{REFERENCES}

Ahlmann, H.W., and Tveten, A. 1923. The recrystallization of snow into firn and the glaciation of the latter. Geografiska Annaler, Arrg. 5, Ht. 1, p. 52-58.

Anderson, E.A. 1976. A point energy and mass balance model of a snow cover. NOAA Technical Report NWS 19.

Angervo, J.M. 1952. Lumitutkimuksesta. Terra, Årg. 64, No. 4, p. 117-24.

Angström, A. 1925. The albedo of various surfaces of ground. Geografiska Annaler, Arg. 7, Ht. 4, p. 322-42.

Bader, H., and others. 1939. Der Schnee und seine Metamorphose, by H. Bader, R. Haefeli, E. Bucher, J. Neher, O. Eckel, and C. Thams. Beiträge zur Geologie der Schweiz. Geotechnische Serie. Hydrologie, Lief. 3.

Bekker, M.G. 1951. Snow studies in Germany. Ottawa, National Research Council of Canada. Associate Committee on Soil and Snow Mechanics. (Technical Memorandum No. 20.)

Budd, W.F. 1966. The drifting of nonuniform snow particles. (In Rubin, M.J., ed. Studies in Antarctic meteorology. Washington, DC, American Geophysical Union, p. 59-70. (Antarctic Research Series, Vol. 9.))

Church, J.E. 1914. Recent studies on snow in the United States. Quarterly Journal of the Royal Meteorological Society, Vol. 40, p. 43-52.

Cummings, W.A. 1952. The dielectric properties of ice and snow at 3.2 centimeters. Journal of Applied Physics, Vol 23 , No. 7 , p. $768-73$.

Dyunin, A.K. 1967. Fundamentals of the mechanics of snow storms. (In Ōura, H., ed. Physics of snow and ice. International Conference on Low Temperature Science ... 1966 ... Proceedings, Vol. 1. Pt. 2. [Sapporo], Hokkaido University. Institute of Low Temperature Science, p. 1065-73.)

Ferrara, G. 1916. Snow. Teramo, A. de Corolis.

Haefeli, R. 1937. Bericht über die wissenschaftliche Tätigkeit der Station Davos-Weissfluhjoch in den Jahren 1934-1937. Schweizer Bauzeitung, Bd. 110, Nr. 8, p. 87-91.

Horton, R.E. 1915. The melting of snow. Monthly Weather Review, Vol. 43, p. 599-605.

Japanese Society of Snow and Ice. 1949. Ten years of snow and ice research. Tokyo, Tokai. [In Japanese.]
Johnson, H., and Bader, H. 1947. Report on snow research in Switzerland and comments on the military significance of snow. New Brunswick, NJ, Rutgers University.

Karpov, A.N. 1936. O mekhanizme snegotaianiio. [On the mechanism of snow melting]. Meteorologiya $i$ Gidrologiya, Tom 2, Vyp. 11, p. 83-85.

Kuz'min, P.P. 1961. Protsess tayaniya snezhnogo pokrova [Melting of snow cover]. Leningrad, Gidrometeorologicheskoye Izdatel'stvo.

Legget, R.F. 1949. Canadian interest in snow and ice research. Ottawa, National Research Council of Canada. Associate Committee on Soil and Snow Mechanics, p. 40-60. (Technical Memorandum No. 14.))

Loewe, F. 1927. Radiation and temperature measurements at the Lötschenlocke in August 1926. Beiträge zur Physik der freien Atmosphäre, Bd. 13, p. 183-97.

Mellor, M. 1975. A review of basic snow mechanics. [Union Géodésique et Géophysique Internationale. Association Internationale des Sciences Hydrologiques. Commission des Neiges et Glaces.] Symposium. Mécanique de la Neige. Actes du Colloque de Grindelwald, Avril 1974, p. 251-91. (IAHS-AISH Publication No. 114.)

Paulcke, W. 1938. Praktische Schnee- und Lawinenkunde. Berlin, Julius Springer.

Quervain, M. de. 1950. Schnee und Schneeprobleme auf dem amerikanischen Kontinent. (In Schnee und Lawinen im Winter 1948-49. Winterberichte des Eidg. Institutes für Schnee- und Lawinenforschung, Nr. 13, p. 111-13.)

Quervain, M. de. 1963. On the metamorphism of snow. (In Kingery, W.D., ed. Ice and snow; properties, processes, and applications. Cambridge, MA, MIT Press, p. 377-90.)

Richter, G. 1961. Development of snow studies in the USSR. Union Géodésique et Géophysique Internationale. Association Internationale d'Hydrologie Scientifique. Commission des Neiges et Glaces. Assemblée Générale de Helsinki 25-7-6-8 1960, p. 69-73. (Publication No. 54 de l'Association Internationale d'Hydrologie Scientifique.)

Seligman, G. 1936. Snow structure and ski fields. London, Macmillan.

Sverdrup, H.U. 1936. The eddy conductivity of the air over a smooth snow field. Geofysiske Publikasjoner, Vol. 11 , No. 7.

Tonini, D. 1958. Orientamenti attuali della glaciologia. Scientia, Vol. 93, p. 206-15.

U.S. Army Corps of Engineers. 1956. Snow hydrology. Summary report of the snow investigations. Portland, OR, U.S. Army Engineers. North Pacific Division.

Voellmy, A. 1955. Über die Zerstörungskraft von Lawinen. Schweizerische Bauzeitung, Bd. 73, p. 159-65, 212-17, 246-49 and 280-85.

Yen, Y.-C. 1969. Recent studies on snow properties. Advances in Hydroscience, Vol. 5, p. 173-214.

Yosida, Z., and others. 1955. Physical studies on deposited snow. I. Thermal properties. Contributions from the Institute of Low Temperature Science, No. 7, p. 19-74. 